\title{
Development of a 3-D printing-based cardiac surgical simulation curriculum to teach septal myectomy
}

Joshua L. Hermsen, MD, ${ }^{\mathrm{a}}$ Roderick Yang, MD, ${ }^{\mathrm{b}}$ Thomas M. Burke, PhD, ${ }^{\mathrm{c}}$ Todd Dardas, MD, MS, L. Myria Jacobs, MLIS, ${ }^{b}$ Edward D. Verrier, MD, ${ }^{b}$ and Nahush A. Mokadam, MD

\section{ABSTRACT}

Objective: We sought to develop a 3-D printing-based simulator for teaching extended septal myectomy to trainees in cardiothoracic surgery (clinical postgraduate year 4-7). This procedure is difficult to teach because of generally unfamiliar and highly variable anatomy, limited visibility for the assistant, and significant potential complications.

Methods: A curriculum using multimedia didactics and 3-D print-based patientspecific surgical simulation was implemented. Six identical 3-D prints were constructed for each of 5 consecutive patients. Preoperative septal myectomy was performed on each printed heart by an attending surgeon and 5 residents. Model myectomy specimen volumes were measured according to liquid displacement. All print resections were videotaped and blindly evaluated by 3 attending surgeons. Pre- and post-test evaluations, and a survey tool were also used to evaluate the curriculum.

Results: Baseline myectomy resection volumes differed significantly (attending $15 \mathrm{~cm}^{3}$ vs resident $3.1 \mathrm{~cm}^{3} ; P<.05$ ). Residents resected increasingly larger volumes of tissue over the course of the study. Initial resection volume (compared with faculty) increased by $0.82 \mathrm{~cm}^{3}$ per resection $(95 \%$ confidence interval, $\left.0.37-1.3 \mathrm{~cm}^{3} ; P<.0001\right)$. Total resection volume (compared with faculty) increased by $3.6 \mathrm{~cm}^{3}$ per resection (95\% confidence interval, 2.4-4.9 $\mathrm{cm}^{3}$; $P<.0001)$. The residents' survey assessment of the simulator was favorable.

Conclusions: A patient-specific 3-D printing-based simulation module shows promise as a tool to augment and improve cardiothoracic resident training in septal myectomy. The residents were quickly able to perform resections on par with the attending. Residents rated the simulator favorably. Each resident benefited by experiencing the variable anatomy of 5 separate patient-specific models. (J Thorac Cardiovasc Surg 2018;156:1139-48)

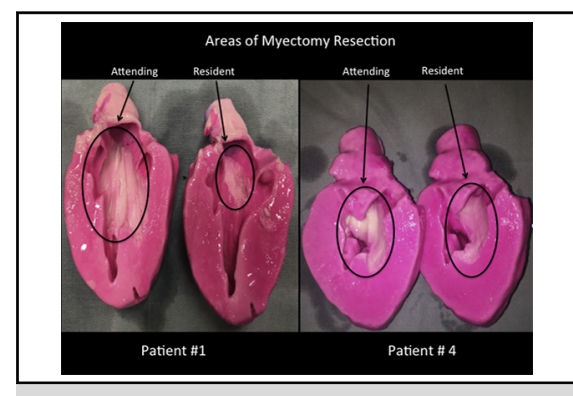

Myectomy done by attending and resident at the beginning (left) and near the end of the study (right). Black circles show the area of resection.

\section{Central Message}

A 3-D print-based simulation curriculum was used to augment cardiothoracic resident training in septal myectomy.

\section{Perspective}

Septal myectomy is a difficult procedure to teach in most training programs because of low surgical volume, generally unfamiliar and highly variable anatomy, limited visibility for the assistant, and significant specific complications. A simulation curriculum using patientspecific 3-D prints is useful to augment resident education and training for this specific procedure

See Editorial Commentary page 1149

See Editorial page 1137.

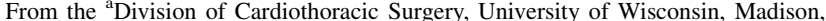
Wis; Divisions of ${ }^{\mathrm{b}}$ Cardiothoracic Surgery, and ${ }^{\mathrm{d}}$ Cardiology, University of Washington, Seattle, Wash; and ${ }^{\mathrm{c}}$ Thomas Burke PhD Consultant, LLC, Seattle, Wash.

This work was funded by The Western Thoracic Surgical Association's 2016 Donald B. Doty educational grant.

Read at the 43rd Annual Meeting of The Western Thoracic Surgical Association, Colorado Springs, Colorado, June 21-24, 2017.

Received for publication June 21, 2017; revisions received Aug 28, 2017; accepted for publication Sept 13, 2017; available ahead of print July 17, 2018.

Address for reprints: Joshua L. Hermsen, MD, Division of Cardiothoracic Surgery, University of Wisconsin, 600 Highland Ave, Clinical Sciences Center, H4/352,

Madison, WI 53792 (E-mail: hermsen@surgery.wisc.edu).

$0022-5223 / \$ 36.00$

Copyright (C) 2017 by The American Association for Thoracic Surgery

https://doi.org/10.1016/j.jtcvs.2017.09.136
Surgical myectomy for treatment of left ventricular outflow tract (LVOT) obstruction in patients with hypertrophic cardiomyopathy is a conceptually simple, yet challenging 3-D procedure. Septal myectomy is difficult to teach compared with many cardiac procedures because of highly variable anatomy that is generally unfamiliar to residents, limited

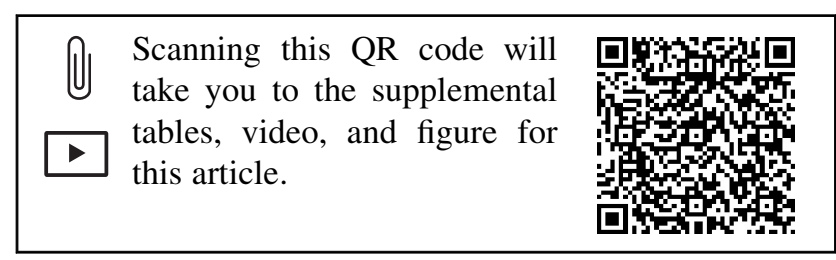




\section{Abbreviations and Acronyms \\ $\mathrm{CABG}=$ coronary artery bypass grafting \\ $\mathrm{CI}=$ confidence interval \\ LVOT $=$ left ventricular outflow tract \\ VSD $=$ ventricular septal defect}

visibility for the assistant, significant specific complications, and low surgical volume in all but a few institutions. ${ }^{1}$

We previously reported on the use of patient-specific 3-D printed models for deliberate practice and surgical rehearsal (by an attending surgeon) of extended septal myectomy for hypertrophic cardiomyopathy. ${ }^{2}$ The models are printed in a proprietary hydrogel medium and are able to be manipulated in ways meaningful to a surgeon. This medium is overall stiffer and less deformable than myocardium but is able to be incised, cut, and sutured. It was apparent from the initial experience that this model might also have educational utility. ${ }^{2}$ The objective of this study was to development and use a 3-D print-based simulation curriculum to augment traditional instruction of senior cardiothoracic residents regarding extended septal myectomy. We recognized our own residents were undertrained in this procedure and hypothesized that a simulation-based curriculum using patient-specific 3-D printed models might have utility.

Within surgical disciplines, teaching and learning of specific procedures are paramount and educational paradigms and pedagogy continue to evolve. Simulation has become increasingly used as an adjunct to operating room experience and the concept of deliberate practice is gaining traction among surgeon-educators. ${ }^{3,4}$

\section{METHODS}

\section{Curriculum}

Cognitive assessment. Each resident completed a 10 item pretest (Appendix E1) before the didactic lectures. The test was readministered at the completion of the curriculum (after all simulations and cases) and scores were compared.

Didactics. A curriculum composed of 2 didactic lectures ( 1 by a cardiac surgeon experienced in myectomy and 1 by a radiologist with 3-D printing expertise), selected readings, ${ }^{5-7}$ and a surgical video ${ }^{8}$ was designed and implemented. The readings and video were provided electronically and the lectures given before beginning the simulation portion of the curriculum.

Simulations. For each of 5 patients who were to undergo myectomy, 6 identical 3-D printed models were constructed. The methodology for printing and performing myectomy on the printed models has been previously published. ${ }^{2}$ Extended septal myectomy of the printed model was performed by an attending surgeon and each of the 5 study residents (Figure 1, Video 1). The attending and each resident performed resection on separate models for all 5 patients (30 models). All model resections were videotaped. Each resection began with identification of the relevant anatomy including the right coronary ostium, right coronary cusp aortic annulus, membranous ventricular septum, and right and left fibrous trigones. The volume of print resected was measured according to liquid displacement in all cases. Measurements were taken of the initial piece

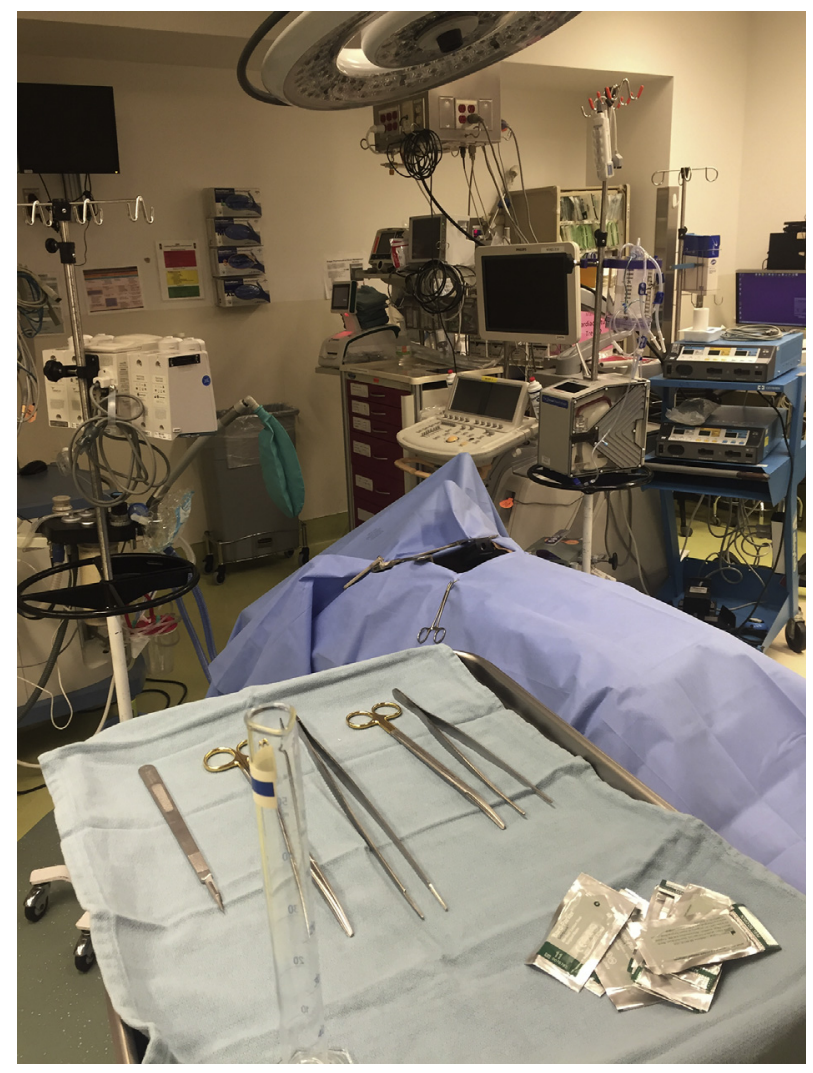

FIGURE 1. Photograph showing the setup of the simulator within an empty operating room. The 3-D print is positioned within a basin placed in the chest cavity of a mannequin. A sternal retractor and drapes help to recreate the field. Basic instruments and the graduated cylinder used to measure resection volumes are shown on the Mayo stand.

resected as well as the total volume of resection specimen. We assessed differences between faculty and resident resections over the course of the experiment using mixed effects linear regression with random intercepts for each resident.

No technical instruction, other than provided in the didactic materials, was given before resection of patient 1 models. This allowed for the resident resection of that model to serve as a baseline. All residents reviewed the patient 1 attending model alongside a representative patient 1 resident model before working with the patient 2 model. Some basic technical feedback was given during patients 3 to 5 model simulation sessions. This feedback was provided by J.L.H., who was the attending surgeon on all cases and was also one of the video graders.

The entire study was conducted during an approximate 6-month period. The time between the didactics and first patient was approximately 3 weeks. The remainder of the patients were spread relatively evenly over the ensuing 5 months.

Faculty scored all model resection videos using a Likert scale-based tool with clinical performance anchors (Appendix E2). Scores were analyzed using mixed effects in a similar fashion. All faculty assessment scores were averaged to provide a mean faculty assessment score for each resident, for each model. Assessment of faculty agreement was performed using the mean faculty assessment score adjusting for fixed effects at the resident and model levels. A logistic regression model was used to model faculty status according to faculty assessment mean scores.

Survey assessment. An anonymous survey tool was developed, on the basis of a tool used for a similar simulation study, ${ }^{9}$ and administered 
after completion of the curriculum. The tool asked residents to assess several domains of the simulator including physical attributes and realism, ability to perform key tasks, readiness for educational use, value as a teaching tool, and worthiness related to effort and future practice.

Institutional review board approval was waived for this study. All residents assented to full participation in the curriculum.

\section{RESULTS}

\section{Cognitive Assessment}

The pre-curriculum mean test score was 5.4 (SD, 2.61), which increased to $7(\mathrm{SD}, 0.89)$ for the post-test $(P=.04)$. This indicates overall knowledge improvement and retention of knowledge gained during the course of a curriculum spanning several months.

\section{Simulations (Resections)}

Volume of resection was recorded for the initial, usually largest, specimen, as well as the total volume resected for each model. Overall, across all 5 models, initial volumes were significantly different between faculty and residents (Figure 2; mean difference, $2.5 \mathrm{~cm}^{3}$; $\mathrm{SD}, 0.36 \mathrm{~cm}^{3}$; $P<.0001)$. Similarly for the total volumes there was a significant difference between faculty and residents (Figure 3; mean difference, $8.6 \mathrm{~cm}^{3}$; $\left.\mathrm{SD}, 1.3 \mathrm{~cm}^{3} ; P<.0001\right)$. Residents resected increasingly larger volumes of tissue over the course of the study. Initial resection volume (compared with faculty) increased by $0.82 \mathrm{~cm}^{3}$ per resection (Figure 4; 95\% confidence interval [CI], 0.37-1.3 $\mathrm{cm}^{3}$; $P<.0001$ ). Total resection volume (compared with faculty) increased by $3.6 \mathrm{~cm}^{3}$ per resection (Figure 5; 95\% CI, 2.4-4.9 $\left.\mathrm{cm}^{3} ; P<.0001\right)$. This difference is despite the fact that the faculty resection volume was the greatest for model 1 and the least for model 5 just on the basis of the differing patient morphology and random order of clinical presentation.

Agreement between the simulated and patient resection volumes was similar to that reported in our previous

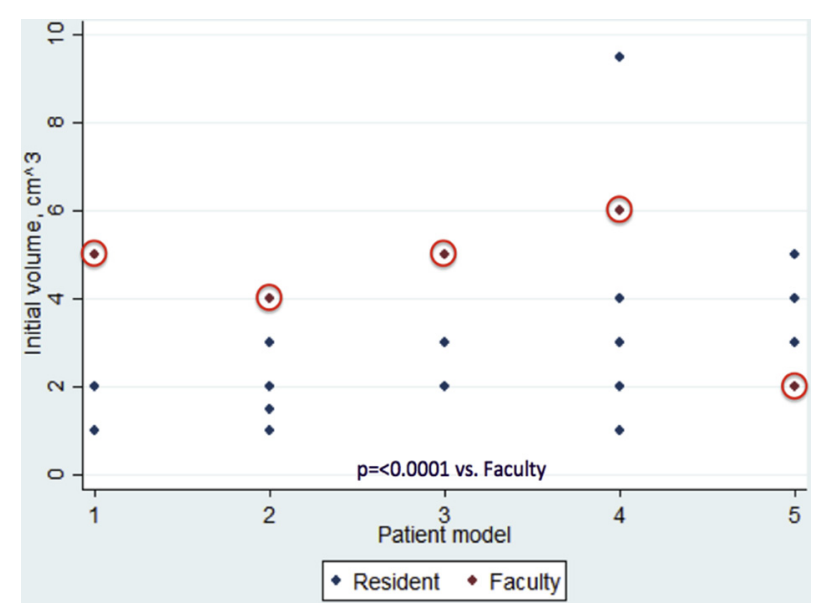

FIGURE 2. Plot showing volumes of "initial" resection specimen for each 3-D printed model. A circle surrounds the faculty data point.

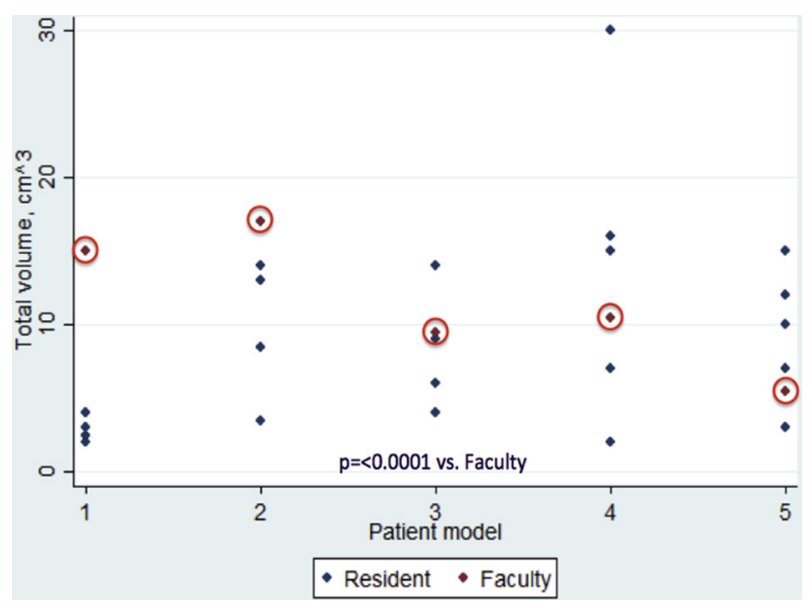

FIGURE 3. Plot showing volumes of "total" resection specimen for each 3-D printed model. A circle surrounds the faculty data point.

experience. ${ }^{2}$ No patient left the operating room with an LVOT velocity $>2 \mathrm{~m} / \mathrm{s}$.

\section{Simulations (Video Assessments)}

Agreement between faculty assessments was poor (Figure $6 ; P<.0001$ ) with rater 3 having significantly higher ratings compared with rater $1(-0.93 ; 95 \% \mathrm{CI},-1.3$ to $-0.58)$ and rater $2(-0.9 ; 95 \% \mathrm{CI},-1.3$ to -0.55$)$. Excluding the faculty member who rated himself, who was also the sole faculty member performing the model resections, faculty assessment scores did not identify faculty status $(P=.72)$.

\section{Survey}

Survey responses were categorized into values between 1 (poor) and 5 (excellent) for all domains. The median response was 4 (interquartile range, 4-5) and response

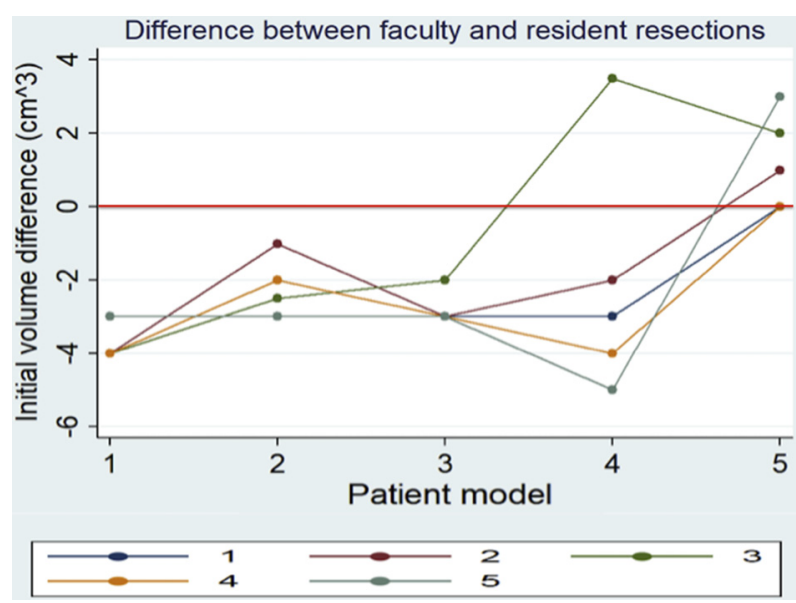

FIGURE 4. Plot showing change in volume of "initial" resection specimen for residents (compared with faculty) over the course of the study. Each colored line represents a resident during the study. The red zero line corresponds to the faculty resection volume. 


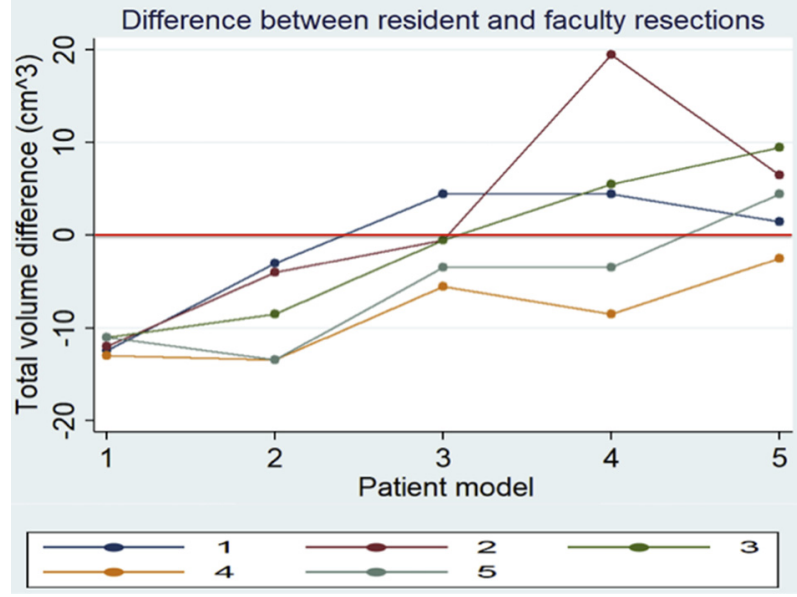

FIGURE 5. Plot showing change in volume of "total" resection specimen for residents (compared with faculty) over the course of the study. Each colored line represents a resident during the study. The red zero line corresponds to the faculty resection volume. mean was 4.31 (SD, 0.66; standard error, 0.67) indicating an overall favorable assessment. Table 1 shows a summary of survey responses for domains relating to physical attributes of the prints and the realism of the simulation experience. Tables E1-E4 show survey results for other domains.

\section{DISCUSSION}

Three-dimensional printing in surgical specialties continues to evolve and has been applied in multiple specialties. Its use in cardiac surgery has been largely focused on congenital disease because the anatomy is often unusual, and there is a limited time to visualize, decipher, and make decisions while the patient's heart is arrested. ${ }^{10,11}$ The advancement in print media and anatomic detail over the past 5 years has been substantial. ${ }^{11,12}$ Other surgical specialties have similarly begun to use 3-D printing for simulation, or surgical rehearsal, of uncommon or unusual procedures because of the known relationships between

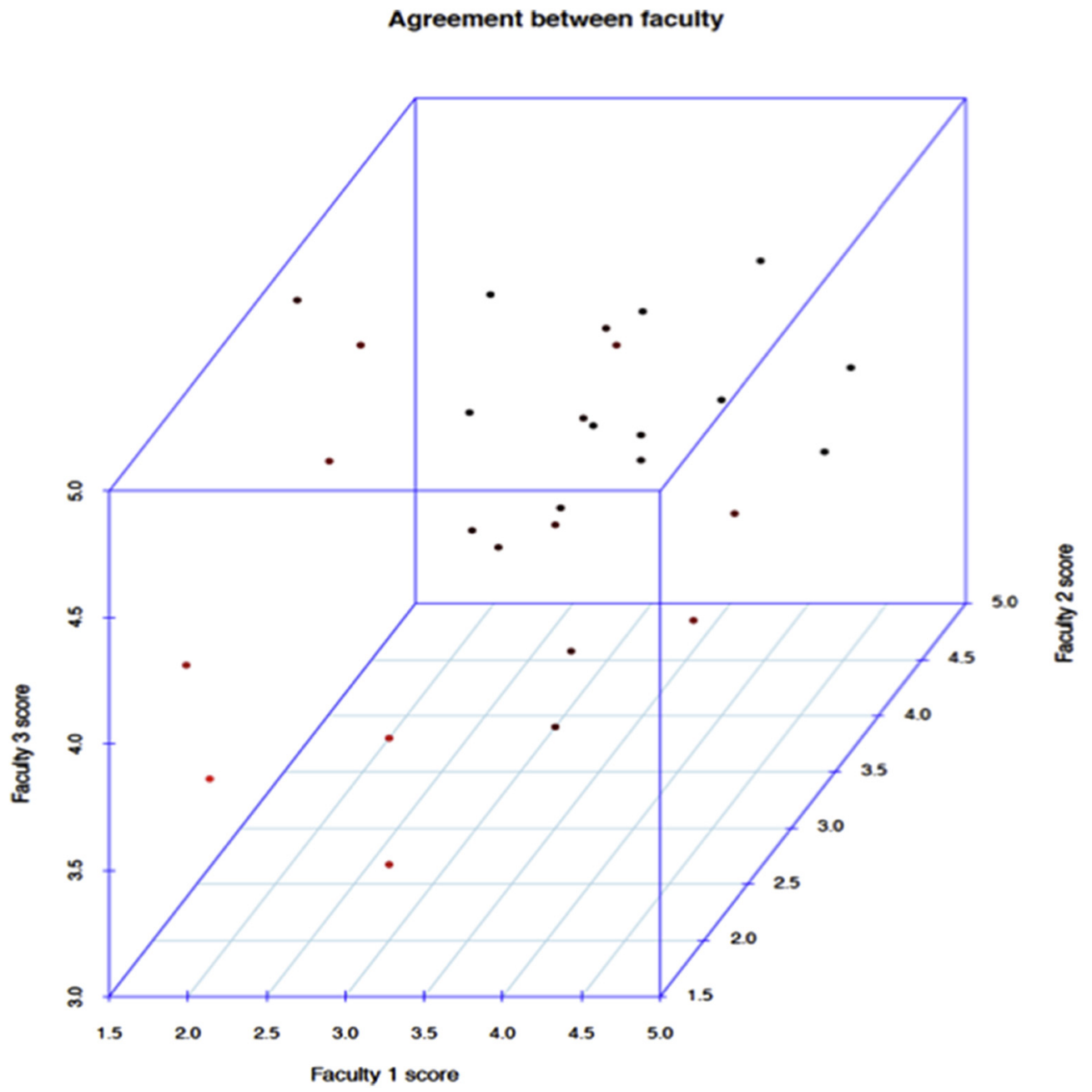

FIGURE 6. Three-dimensional box plot showing poor correlation between video scores assigned by 3 faculty reviewers. 
TABLE 1. Survey responses for domains relating to physical attributes of the prints and the realism of the simulation experience

\begin{tabular}{|c|c|c|c|c|c|}
\hline Domain & $\begin{array}{l}\text { Don't } \\
\text { know }\end{array}$ & $\begin{array}{c}\text { Not at } \\
\text { all realistic }\end{array}$ & $\begin{array}{c}\text { Mildly } \\
\text { realistic, but not } \\
\text { enough for this use }\end{array}$ & $\begin{array}{c}\text { Moderately } \\
\text { realistic, enough } \\
\text { for this use }\end{array}$ & $\begin{array}{l}\text { Highly realistic, } \\
\text { enough for this use }\end{array}$ \\
\hline \multicolumn{6}{|l|}{ Physical attributes } \\
\hline Chest depth & - & - & - & 100 & - \\
\hline \multicolumn{6}{|l|}{ Landmark visualization } \\
\hline RCA os & - & - & - & 60 & 40 \\
\hline Annulus & - & - & - & 80 & 20 \\
\hline Membranous septum & - & - & 20 & 80 & - \\
\hline Right trigone & - & - & - & 100 & - \\
\hline Left trigone & - & - & - & 100 & - \\
\hline Septal visualization & - & - & - & 60 & 40 \\
\hline \multicolumn{6}{|l|}{ Realism of materials } \\
\hline Tissue quality & - & - & 40 & 60 & - \\
\hline \multicolumn{6}{|l|}{ Realism of experience } \\
\hline Realism of surgical approach & - & - & 20 & 60 & 20 \\
\hline Realism of surgical angles & - & - & - & 80 & 20 \\
\hline Realism of ability to manipulate tissue & - & 20 & - & 80 & - \\
\hline Realism of response to scalpel & - & - & 40 & 60 & - \\
\hline Realism of septal anatomy & - & - & - & 60 & 40 \\
\hline Realism of overall experience & 20 & - & - & 60 & 20 \\
\hline
\end{tabular}

Data are presented as percentages. $R C A$ os, Right coronary artery ostium.

volume and outcome. ${ }^{13}$ Neurosurgeons have developed high-fidelity 3-D printed models to simulate aneurysm clipping, and have shown agreement in clip selection between simulations and actual procedures. ${ }^{14}$ Orthopedists have shown simulation of tibial plateau fracture repair using a patient-specific 3-D print to decrease surgery times. ${ }^{15}$

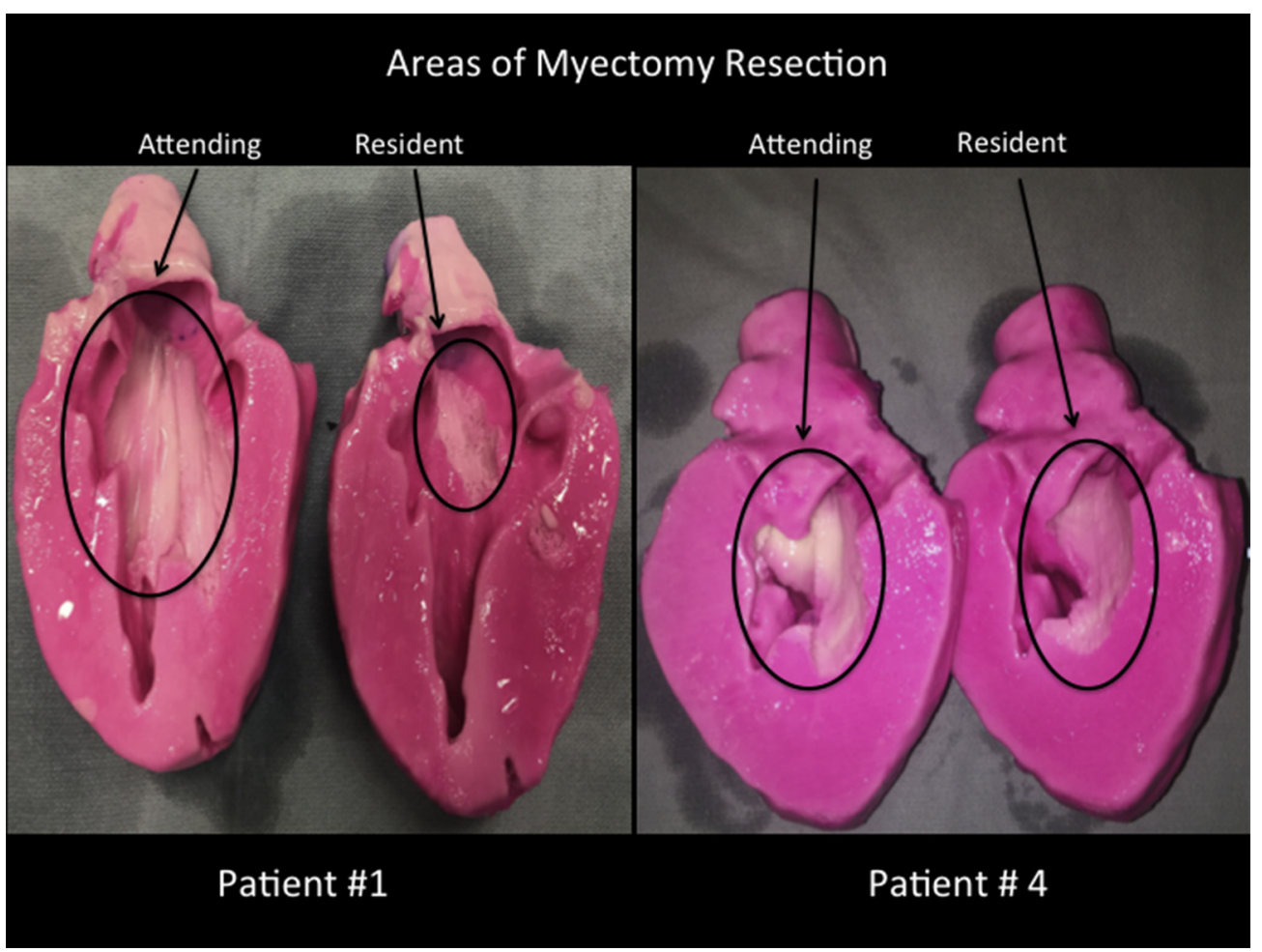

FIGURE 7. Images of 3-D printed models after myectomy by faculty and residents. The left panel shows faculty and resident models for patient 1 and the right panel shows faculty and resident models for patient 4 . 


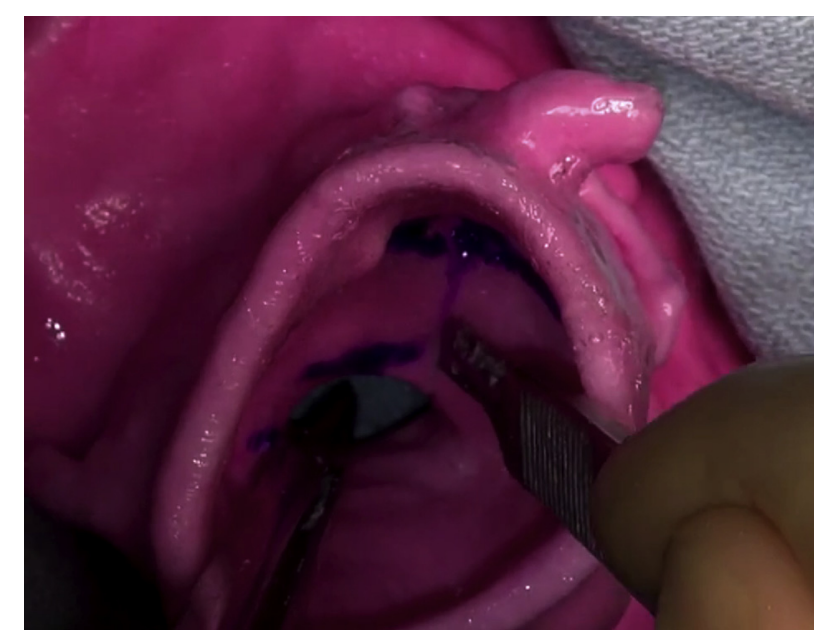

VIDEO 1. Video clip showing a resident myectomy on a 3-D print. The resident begins by marking the right coronary ostium (correctly), the annulus of the right coronary sinus of Valsalva (correctly), and the membranous septum (incorrectly). The rightward extent of myectomy is correctly identified as a line drawn from the right coronary ostium down to the annulus. Resection of the initial piece of septum is shown. Video available at: https://www.jtcvs.org/article/S0022-5223(17)32407-8/fulltext.

The hypothesis that residents are undertaught in this procedure was generally confirmed with the results of the first simulation of the series, which served as a baseline assessment. Uniformly, the residents resected a very small total volume of septal tissue $\left(2.5-4.0 \mathrm{~cm}^{3}\right)$. This would have constituted a sham procedure, because the actual volume resected at surgery was greater by at least 4 -fold $\left(15 \mathrm{~cm}^{3}\right.$; Figure 7, left image). The resident resections for patient 1 were generally inadequate even for all other patients considering faculty resection volumes of $17,9.5,10.5$, and $5.5 \mathrm{~cm}^{3}$ for the 4 other models, respectively. However, although the resection volumes in aggregate (for all study patients) were significantly different between attending and resident, the residents clearly made progress with accumulation of experience performing myectomy on the models as shown by significant increases in the volumes of resection.

Importantly, the subjective qualities (shape, depth, apical extent) of the resident resections also improved during the study and were much more on par with the attending resection at the end of the study (Figure 7, right image). This is significant because the objective of the study was only to perform basic evaluation of the model as a platform for education. Therefore, residents were not formally instructed or coached during their model resections. Either purely visual (comparison of attending and resident models for patient 1 before working on patient 2) or relatively generic feedback, such as "create an edge of specimen to retract posteriorly then flatten the knife angle to proceed more apically," was given during the study. We speculate that the act of doing the model resections provided the residents a more educated lens through which to view and mentally engage during each subsequent model, creating a type of positive feedback loop, which translated to improving resections as the study progressed. This simulation platform seems poised, with more focused and real-time coaching and feedback, to be an excellent tool for instruction in extended septal myectomy.

As discussed in a previous related publication, many porcine hearts used in cardiac surgery simulation curricula possess asymmetric basilar septal hypertrophy that might allow for meaningful myectomy. ${ }^{2}$ However, the internal dimensions, working space, and angles afforded by these hearts would likely not translate well to human patients. Additionally, the patient-specific nature afforded by the 3-D printed models would be lost. In a disease with such variable relevant morphology, the patient-specific nature of a simulation or surgical rehearsal is important. Even with only 5 patients, the variability of phenotype in hypertrophic cardiomyopathy was on display. In each case, a very similar section of heart and aorta was printed, and these print volumes ranged from $137 \mathrm{~cm}^{3}$ to $289 \mathrm{~cm}^{3}$.

The results of the survey (Table 1 and Tables E1-E4) were encouraging. Although the materials used to produce the prints can definitely be improved and become more tissue-like, most of the residents thought it adequate for this purpose. The "face validity" of the simulator was also judged favorably on the basis of the realism scores related to recreation of the surgical approach and working angles. Most importantly, most of the residents thought the simulations were worth the time and effort expended (approximately 30 minutes for each model, usually in the midst of a busy clinical day) and would enable them to perform myectomy with senior partner assistance when entering practice. Additionally, each resident benefited from the anatomy of 5 different patients, by performing simulations on each of the 5 models, although they each operated on only 1 patient.

\section{Limitations}

This is a relatively small study in number of patients and residents. Cost is currently a barrier for more widespread use of this technology. For this study, 30 models were printed at a total cost of approximately $\$ 8000$ USD (approximately $\$ 270$ per model). The print material technology is still suboptimal as was noted by our residents and has been noted by others using 3-D cardiac prints for surgical simulation. $^{11}$

\section{Future Directions}

This experience represents a small "library" of cases because an adequate patient resection volume, inferred from excellent surgical results, is known. Such a series of cases could easily be reprinted as a "case series" for another learner to work through. If paired with surgical 
videos (an answer key of sorts), a learner could perform a resection, measure the volumes, and then review the video for comparison with the actual patient outcome. This curriculum could quite easily be integrated into established cardiac surgical simulation programs as a learning module, similar to existing modules focused on aortic valve replacement or coronary artery bypass grafting (CABG) ${ }^{16,17}$ Additionally this model could provide feedback regarding excessive resection and creation of a ventricular septal defect (VSD). The model is not well equipped in the current configuration to simulate VSD repair because the right atrium and tricuspid valve are not included in the print.

\section{CONCLUSIONS}

The ability for residents to engage in deliberate practice on 3-D prints representing "real anatomy," and to compare their resection to one done by an attending surgeon on an identical print might provide a new paradigm to enable improved training in myectomy surgery. Because of the difficulty in teaching this procedure to residents with the "see one, do one, teach one" model, this might help to fill an important training gap in most resident's surgical repertoire. Although 3-D printing technology is not yet sufficient to provide meaningful simulation for more commonly performed CABG or valve procedures, it is well suited, and might find a niche as a simulation platform for septal myectomy.

\section{Conflict of Interest Statement}

Dr Hermsen's spouse is a paid consultant for Medtronic. Dr Burke is the owner of a for profit corporation that manufactures patient-specific heart models and received reimbursement for materials used in producing heart models for this study. Dr Mokadam is a consultant for Medtronic and Abbott, and an investigator for Medtronic, Abbott, and Syncardia. All other authors have nothing to disclose with regard to commercial support.

\section{References}

1. Maron BJ, Rastegar H, Udelson JE, Dearani JA, Maron MS. Contemporary surgical management of hypertrophic cardiomyopathy, the need for more myectomy surgeons and disease-specific centers, and the Tufts initiative. Am J Cardiol. 2013;112:1512-5.

2. Hermsen JL, Burke TM, Seslar SP, Owens DS, Ripley BA, Mokadam NA, et al. Scan, plan, print, practice, perform: development and use of a patient-specific 3dimensional printed model in adult cardiac surgery. J Thorac Cardiovasc Surg. 2017;153:132-40.

3. Mokadam NA, Fann JI, Hicks GL, Nesbitt JC, Burkhart HM, Conte JV, et al. Experience with the cardiac surgery simulation curriculum: results of the resident and faculty survey. Ann Thorac Surg. 2017;103:322-8.

4. Cook MR, Graff-Baker AN, Moren AM, Brown S, Fair KA, Kiraly LN, et al. A disease-specific hybrid rotation increases opportunities for deliberate practice. J Surg Educ. 2016;73:1-6.

5. Smedira NG, Lytle BW, Lever HM, Rajeswaran J, Krishnaswamy G, Kaple RK, et al. Current effectiveness and risks of isolated septal myectomy for hypertrophic obstructive cardiomyopathy. Ann Thorac Surg. 2008;85: 127-34.
6. Maron BJ, Ommen SR, Semsarian C, Spirito P, Olivotto I, Maron MS. Hypertrophic cardiomyopathy: present and future, with translation into contemporary cardiovascular medicine. J Am Coll Cardiol. 2014;64:83-99.

7. Schaff HV, Said S. Transaortic extended septal myectomy for hypertrophic cardiomyopathy. Op Tech Thor Cardiovasc Surg. 2012;17:238-50.

8. YouTube. Video of my heart surgery (myectomy). Available at: https://www. youtube.com/watch? $=$ a0BJdYcV32Q\&t=. Accessed July 3, 2018.

9. Barsness KA, Rooney DM, Davis LM. Collaboration in simulation: the development and initial validation of a novel thoracoscopic neonatal simulator. $J$ Pediatr Surg. 2013;48:1232-8.

10. Oliveiri LJ, Su L, Hynes CF, Krieger A, Alfares FA, Ramakrishnan K, et al "Just-in-time" simulation training using 3-D printed cardiac models after congenital cardiac surgery. World J Pediatr Congenit Heart Surg. 2016;7:164-8.

11. Yoo SJ, Spray T, Austin EH, Yun TJ, van Arsdell G. Hands-on surgical training of congenital heart surgery using 3-dimensional print models. J Thorac Cardiovasc Surg. 2017; 153:1530-40.

12. Shiraishi I, Yamagishi M, Hamaoka K, Fukuzawa M, Yagihara T. Simulative operation on congenital heart disease using rubber-like urethane stereolithographic biomodels based on 3-D datasets of multislice computed tomography Eur J Cardiothorac Surg. 2010;37:302-6.

13. Mamidanna R, Ni Z, Anderson O, Spiegelhalter SD, Botle A, Aylin P, et al. Surgeon volume and cancer esophagectomy, gastrectomy, and pancreatectomy: a population based study in England. Ann Surg. 2016;263:727-32.

14. Wang L, Ye X, Hao Q, Chen Y, Chen X, Wang H, et al. Comparison of two threedimensional printed models of complex intracranial aneurysms for surgical simulation. World Neurosurg. 2017;103:671-9.

15. Lou Y, Cai L, Wang C, Tang Q, Pan T, Guo X, et al. Comparison of traditional surgery and surgery assisted by three dimensional printing technol ogy in the treatment of tibial plateau fractures. Int Orthop. 2017;41: 1875-80.

16. Feins RH, Burkhart HM, Conte JV, Coore DN, Fann JI, Hicks JL, et al Simulation-based training in cardiac surgery. Ann Thorac Surg. 2017; 103:312-21.

17. Feins RH, Burkhart HM, Coore DN, Conte JV, Fann JI, Hicks GL, et al, eds. Cardiac Surgery Simulation Curriculum. Chapel Hill, NC: Lulu; 2015.

Key Words: simulation, surgical education, septal myectomy, hypertrophic cardiomyopathy, 3-D printing

\section{Discussion}

Moderator. Our next paper is entitled, "Development of a 3-D printing-based cardiac surgical simulation curriculum to teach septal myectomy." It will be presented by one of our new members, Joshua Hermsen from the University of Washington.

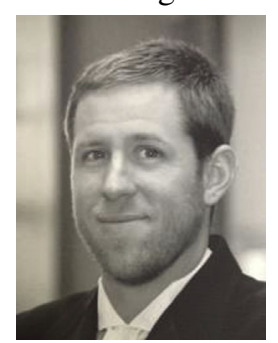

Dr Joshua Hermsen (Madison, Wis). Great. Thank you. It's an honor to stand here this morning and share our work and thanks to the program committee and moderators. So, my wife gets paid by Medtronic to basically buff up their HR PowerPoints so nothing medically conflicting, and the engineer we work with hopes to one day get paid for some of his expertise.

At this meeting last year we presented some early work using patient-specific 3-D printed models, basically as an operative rehearsal for septal myectomy and showed that we could do it and using liquid displacement measure the resection volumes from the models in the patients, and they were fairly equivalent. And we thought there were 
several applications of this technique, but we thought the biggest bang for the buck in the short-term was as a resident education tool because we find this operation extremely difficult to teach our residents mainly because the person with the knife is the only person that can see what's going on. Before last year's meeting, we applied for, and Dr Nahush Mokadam was awarded the Doty Educational Award from this association, and that money completely funded the work we've done over the past year. Our goal is to design and evaluate a simulation-based curriculum, using patientspecific 3-D models to better train our residents and extend in septal myectomy for patients with hypertrophic cardiomyopathy. We quickly got to work designing a curriculum that was built around these simulations that included a 10item cognitive assessment used as a pre- and a post-test. I gave a lecture to our residents and had one of our radiologists with expertise in 3-D printing give a lecture. I selected 5 readings from major journals and a YouTube video from a world expert performing the procedure that the residents watched. And then, there were 5 patients that we did the simulations for and a survey at the end. The simulations using the 3-D prints were performed on the 5 consecutive patients. We printed 6 models per patient. The operating surgeon, who was the same for all of these patients, performed resection on the model and each of 5 senior cardiothoracic surgical residents performed a resection. All resections were videotaped with a headlight-mounted high-definition camera and the volume of initial resection, which was each of the dominant piece, and the total resection specimen were measured according to liquid displacement in a graduated cylinder. We developed this assessment tool to grade the videos and you can see the first part of each video was the identification of the important anatomy, so the right coronary os, the right coronary cusp, the anulus, and membranous septum, and the trigones, and then we also tried to evaluate the use of scalpel and forceps in cutting out and handling the specimen, as well as some assessment of the quality of the resection in relation to the membranous septum.

So, to recap there was some early education and a pretest. For each patient, there were the 6 models and the simulations, and the video assessments and then a post-test and a survey. We didn't give any specific instruction before the first model other than that in the lectures so that it could serve as a kind of baseline and then there was feedback in between each subsequent model. This was the feedback I gave after the first model before the second model, just so they could visually see the difference between the attending resection and the resident resection which was all very similar for this first model. Here's a plot showing the resection volumes of the initial, again usually dominant, specimen for all of the resections. The faculty values are shown in the red circle, and not surprisingly, these were significantly different. However, the residents did improve during the course of the study, significantly increasing their initial resection volumes and for the fifth and final patient, equaled or exceeded the faculty resection volume. Similarly, the difference in total resection volumes between faculty and residents was highly significant. And similarly, the residents made significant improvements during the study and by the end of the series, residents were approximating and in some cases exceeding the faculty resection volume as you can see in the fifth patients. Now this operation... just more is not always better, but this image, showing a faculty and resident resection from 1 of the fourth models... or the fourth model... shows that the residents were much more closely approximating the level of faculty resection in these later models.

I'm going to play a video clip from one of the early models that shows some of the power of this type of tool and some of the sort of hidden benefits that you uncover. You're going to see the resident with the marker identify the right coronary ostium, and anulus of the right coronary cusp, and then misidentify the membranous septum and then promptly excise it with his resection. So, then he's going to find the right coronary os, which is pretty easy because we have them print the proximal right coronary, the anulus, and... whoops that's not the right spot. You will see he does correctly identify where to start his resection by coming straight down from the right coronary. And then does a pretty fair job with the scalpel and the forceps in resecting this initial piece but obviously there was some chance there for some constructive criticism in education of where the membranous septum was and then the fact that you can't mark a critical structure and then cut it out, so it's a judgement piece. The results of the video assessments that were again done by 3 separate faculty for all of the videos, resident and attending, were disappointing. There was statistically significant disagreement and basically 0 inter-relator reliability, and excluding the faculty member who was also involved with the resections, the video grading was unable to discern faculty from resident performance. The residents did show improvement on the post-test, indicating they gained and had some at least short-term retention of knowledge, although I'd say a mean score of 7 is still not great. And the survey results were actually very encouraging and so we tried to get at did they think the models accurately represented the anatomy? And then did they think the experience of the simulation was somewhat realistic? And 34 of 35 possible responses as far as the anatomy indicated that it was adequate for this current purpose and $80 \%$ of the responses indicated that they thought it was realistic enough for this purpose at their level. And importantly, all 5 residents unanimously thought that it was worth the effort and these were done usually in the midst of a busy clinical day when an operating room opened up that we could set up in. And they felt empowered, whether appropriately or not, to tackle these cases with senior partner assistance when they got into practice. 
So, in conclusion, we think this is a useful tool for teaching this procedure that is difficult to teach on patients, and I think the residents quickly went from doing sham resections to resections that were potentially therapeutic and on par with the attending. Each resident benefited from seeing the anatomy of all 5 patients and working on all 5 patients, although they only participated in 1 procedure and I wish I had a picture of all 5 models lined up looking down the LVOT because it really highlights the morphologic differences and the variation in these patients. We have to get better materials, and as we do, this type of model will become more useful. And it's still pretty expensive. This costs approximately $\$ 400$ per model and that's obviously going to limit any kind of widespread application anytime soon. Thank you.

Moderator. The discussion will be opened by Dr Craig Baker from USC.

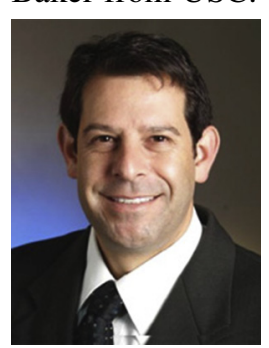

Dr Craig Baker. Thank you. Thank you to the Western for the opportunity to discuss this paper. I want to congratulate Dr Hermsen and his coauthors form the University of Washington on an excellent presentation today, and also to thank them for letting me review the report in advance. I would also like to acknowledge them for the continued effort from our colleagues from University of Washington to improve thoracic education constantly striving for meaningful and novel methods to enhance the training of our residents. Now truthfully, teaching thoracic surgery procedures can post significant challenges, and there is often great variability even among accomplished surgeons in their abilities to allow residents to perform cases. Although most surgeons become comfortable in allowing residents to perform most routine or straightforward cases, there is no doubt that specific procedures or platforms such as minimally invasive surgery, robotics, or in this case septal myomectomy performed in a poorly visualized field can be difficult. So I have 2 questions, which I will ask separately, and really have to do with this model and less about your curricula, which I think you should be commended for developing, and I'll preface my questions with some personal bias in that although I commend you for investigating new technology, which I believe is admirable, I have become somewhat disenfranchised myself with the use of these low-fidelity models to teach cardiac surgery and actually translate that to the operating room except in very low-level learners. So, the first question relates to the general importance of this technology specifically for adult cardiac surgery. Using 3-D printing, you essentially created 30 high-technology but very low-fidelity models at a cost of $\$ 8000$. As you point out in the report, either porcine hearts or even human hearts, which many of our relationship companies are happy to get to us for resident education, could have been used, but they wouldn't actually be replicants of the actual anatomy for the patients on whom you're going to operate. It does seem however, for a CABG or AVR, it wouldn't be that useful for me to define exact lesions if the surgeon understands the principles of coronary vascularization or aortic valve replacement. So, my question to you is how important do you believe it is on a larger scale for our specialty to be able to create these preoperative patientspecific models and if you do believe it's important, can you tell us in what other circumstances you think this might be useful.

Dr Hermsen. Yeah, thank you. I've thought about this a lot, and I think I agree with most of your biases. This kind of thing doesn't make sense for CABG. It doesn't make sense for valve surgery, and we don't have the technology currently to print valves or have the materials to replicate any of the work we actually do. This was the only procedure or application I could think of where it actually seemed to make some sense, because although it's a delicate operation, it's simple and it's purely resective, and again the patient specificity in this disease really matters, less so in $\mathrm{CABG}$, less so in valve replacement operations, and again the ability to have a preview of the anatomy for this procedure I think is a step above for most of the other surgeries we do.

Dr Baker. Thank you, and to that point, the second question relates to the use of this model for dealing with some of the complications of septal myomectomy. As many surgeons know, as you progress in your comfort with septal myomectomy over time, your specimens do tend to get larger as they did in your curricula with your residents. That also potentially increases the risk of VSD, which can be quite challenging if you're not comfortable in how to deal with this. Do you foresee this model being able to be used for residents on how to deal with this complication is one of the main benefits of simulation might be to prepare trainees for a stressful and somewhat rare situation. In other words, because this is an actual replicant of a patient's anatomy, can you use that to show where a VSD would happen depending on how deep you are and use this model to prepare how to deal with it?

Dr Hermsen. Yeah, yes... let me make 1 more point on your first question first, about the pig and human hearts. I think they're complementary because obviously this model, although it replicates the patient's anatomy, it's kind of frozen and the tissue is not very malleable so kind of doing it on a static model and then also kind of walking through on a tissue model where you actually have a better feel of tissue, I think they go together, they're not mutually exclusive. And on the second question about complications, I think... and there was 1 model in particular where... I don't know if it was how it was printed or how it was segmented, but actually there were a couple of VSDs created, so definitely kind of highlighted where that membranous septum is, where 
you get into it, and how easy it is to be injured. Simulating the repair on this model won't really work, because we don't print any of the atrium, and this material is not particularly suturable. This engineer has printed a different model for us, sort of a pediatric-size model with a VSD. We have actually done one of those just on one of my colleagues' desks, sewing a patch on it to see how it was and I think again for a low-level learner that has some benefit and you could couple it with this to say okay, here's a sort of more congenital VSD but it's in the general same location and here's how you would fix it, but this particular model or set of models wouldn't be great to simulate that.

Dr Baker. Does it print the actual RV outflow track, the kind of anterior part of the VSD if you were going to go through the infundibulum and get to the hole, does it print that?

Dr Hermsen. It could. We can print anything we want. Actually, the first one we did print the whole heart, and then we realized it was just too much and a waste of material, so basically just print the aorta and probably the anterior two-thirds of the septum were kind of from trigone to trigone, and basically the front of the heart is just open.

Dr Baker. Again, congratulations for pushing the boundaries and I will defer to Cerf.

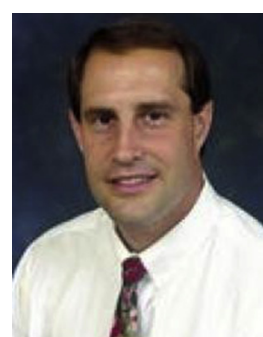

Dr Robert Cerfolio (New York, NY). Robert Cerfolio, New York Langone Medical University. Good job, a couple of questions for you. You practice the way you play and you play the way you practice. There is the technical aspect and there's the cognitive and physical aspects of this. I would challenge you that video review is cheaper and better with no modeling cost. We all know simulation is our future, but our actual future is reviewing videos. So, I got to disclose that I'm a consultant for a company that does that but you can just put these videos online and if you could mount a head-cam and take the time in the OR to make a great view of it, wouldn't that be more instructive for something like this, which as you said, is more resective than technically difficult. Anybody can cut it with a knife, it's where you go. I would challenge you, wouldn't that be more valuable at less cost?

Dr Hermsen. I think that was used. I would challenge you back that there's some value in doing a physical... in practicing how you play and you're going to do a physical procedure so you should simulate it in the physical environment. There is some degree of muscle memory or different angulation for different patients, that can give you some insight, and I guess I would say I wouldn't expect these same outcomes if they had just watched Dr Smedira's video that I found online that was part of the curriculum.
Dr Cerfolio. Even if he went through all the anatomy incredibly carefully and showed you right where to cut and how to do it? And how to take care of all the complications?

Dr Hermsen. I don't think so. I don't think Tom Brady can win 5 Super Bowls if he never practiced on the field.

Dr Cerfolio. Yeah, but you're teaching fellows who aren't Tom Brady exactly, but they're going to get their experience.

Dr Hermsen. True, although as you recall Tom Brady was drafted in the sixth round, and I would submit to you the residents in Seattle are all first rounders.

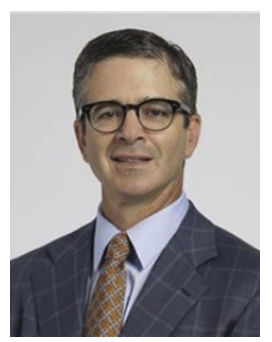

Dr Smedira (Cleveland, Ohio). Smedira, Cleveland Clinic. I think this is a big deal and I congratulate you and your team for working on it. It is a simple procedure but it's one of the most challenging that we do. I personally perform over 2500 myectomies, and it still is a challenge each and every day and the key is understanding the immensity of the anatomic variation of the septum, where the hypertrophy occurs, how deep it goes, so I think this is a big deal for training not only residents, but I've mentored senior surgeons who find it extremely difficult to do this procedure and to do it well, so I don't have a specific question, but I would encourage you to continue, try to get this model so it's reproducible. We just published a paper in JTCVS saying we need more myectomy surgeons in the United States, and the way to get there is to have these types of tools to train our colleagues so that we can do it safely. It looks like a great model and I encourage you to continue that work.

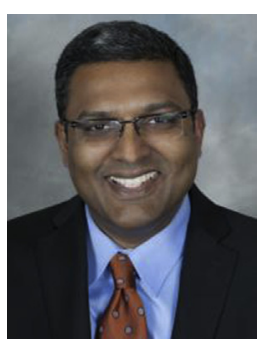

Dr Tom Varghese (Salt Lake City, Utah). I echo, sir, Tom Varghese, Salt Lake City. That's your Tom Brady standing right over there, so I completely agree with the... but he didn't watch a video, he did it 2000 times. Just a quick question, Josh. How long does it take to get 1 model printed out? Is this something that you have to set up overnight because it takes a long period of time for the engineer to print out?

Dr Hermsen. Yeah, it takes a few days in the way he's set up, which is basically, I send him a dicom of the CT and he segments it and then he prints it in his garage and, you know, it can probably be done overnight or 2 nights, but I try to give him a week ahead of time.

Dr Varghese. A week. Thank you.

Dr Hermsen. And thank you Dr Smedira for your comments. It means a lot coming from one of the leaders in this and it's encouraging. Thank you. 


\section{APPENDIX E1. PRE- AND POST-TEST COGNITIVE ASSESSMENT}

1. What is the approximate incidence of hypertrophic cardiomyopathy (HCM) in the United States?
a. $1 / 1000$
b. $1 / 10,000$
c. $1 / 50$
d. $1 / 500$

2. Approximately what percentage of patients with HCM develop atrial fibrillation?
a. $10 \%$
b. $25 \%$
c. $50 \%$
d. $75 \%$

3. Approximately what percentage of patients with HCM develop measurable left ventricular outflow tract obstruction (LVOTO)?
a. $10 \%$
b. $30 \%$
c. $70 \%$
d. $90 \%$

4. What is the most common mechanism of LVOTO in $\mathrm{HCM}$ ?
a. Midcavitary muscular obstruction
b. Apical muscular obstruction
c. Systolic anterior motion of the mitral valve
d. Tunnel-like left ventricular outflow tract (LVOT) ste- nosis

5. Which drug is generally contraindicated in patients with HCM?
a. Verapamil
b. Lisinopril
c. Metoprolol
d. Disopyramide

6. What are the 4 specific surgical complications of myectomy for HCM?

a. Ventricular septal defect (VSD), mitral valve injury, aortic dissection, heart block

b. VSD, mitral valve injury, aortic valve injury, heart block

c. VSD, tricuspid valve injury, aortic valve injury, heart block

d. VSD, postoperative bleeding, aortic valve injury, heart block
7. What electrocardiogram finding would be of most concern on a preoperative myectomy patient?
a. Left bundle branch block
b. Complete heart block
c. Right bundle branch block
d. Chronic $\mathrm{T}$ wave inversion

8. Which LVOT spectral Doppler trace is most consistent with HCM with LVOTO?

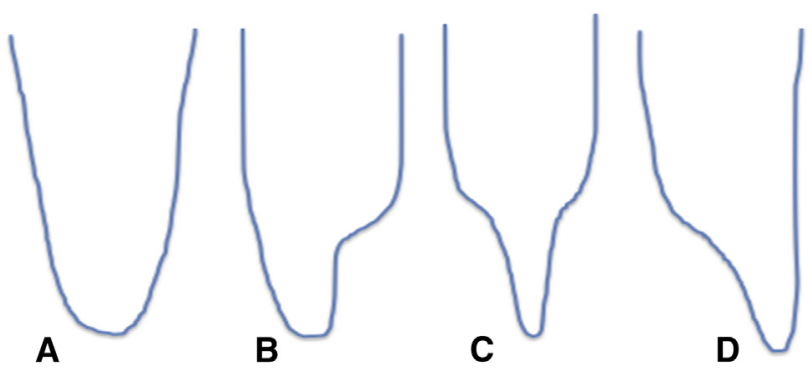

9. What is the difference between continuous (CW) and pulse wave (PW) Doppler?

a. CW measures specific point along ultrasound (US) beam, PW measures along entire beam

b. CW measures along entire US beam, PW measures specific point along US beam

c. CW and PW are differentiated by acquisition frame rate

d. CW is a color Doppler output whereas PW is a spectral Doppler output

10. Which inotrope is most rational for intraoperative use in patients with HCM undergoing myectomy?
a. Dopamine
b. Epinephrine
c. Milrinone
d. None

11. Rate your anticipated comfort with performing myectomy during your first year in practice
a. Would refer to another surgeon
b. Uncomfortable but would perform
c. Mildly uncomfortable
d. Comfortable
e. Confident 


\section{APPENDIX E2}

\section{Three-dimensional print myectomy assessment tool}

Heart \#

Date:

Subject\#

Poor

Excellent

\begin{tabular}{|c|c|c|c|c|c|c|}
\hline \multirow[t]{6}{*}{1.} & Anatomic landmarks & 1 & 2 & 3 & 4 & 5 \\
\hline & Right coronary artery ostium & $0-1$ & 2 & 3 & 4 & All 5 \\
\hline & Right coronary cusp annulus & & & & & \\
\hline & Membranous septum & & & & & \\
\hline & Right trigone & & & & & \\
\hline & Left trigone & & & & & \\
\hline
\end{tabular}

\begin{tabular}{|r|r|r|r|r|c|}
\hline 2. & Use of scalpel 1 & 2 & 3 & 4 & 5 \\
\hline & Injury to key structures & & Some uncertainty & & Precise and accurate \\
\hline
\end{tabular}

\begin{tabular}{|c|c|c|c|c|c|}
\hline 3. & Use of forceps 1 & 2 & 3 & 4 & 5 \\
\hline & Drops specimen & & Inconsistent traction & & Precise and accurate \\
\hline
\end{tabular}

4. Resection volume (initial)

Volume: $\left(\mathrm{cm}^{3}\right)$

5. Resection volume (total)

Volume: $\left(\mathrm{cm}^{3}\right)$

6. Resection volume (perfect)

Volume: $\left(\mathrm{cm}^{3}\right)$

\begin{tabular}{|l|l|c|c|c|}
\hline 7. & Muscular septum 1 1 & 2 & 3 & 4 \\
\hline & Creates ventricular septal defect & & Uneven resection & Uniform resection/residualthickness \\
\hline
\end{tabular}

\begin{tabular}{|c|c|c|c|c|c|}
\hline 8. & Membranous septum 1 & 2 & 3 & 4 & 5 \\
\hline & Direct injury & & Mycetomy within $5 \mathrm{~mm}$ & & Myectomy outside $10 \mathrm{~mm}$ \\
\hline
\end{tabular}


TABLE E1. Survey results for self-rating using the simulator

\begin{tabular}{|c|c|c|c|c|c|}
\hline & $\begin{array}{c}\text { Almost impossible } \\
\text { to perform }\end{array}$ & $\begin{array}{l}\text { Very difficult } \\
\text { to perform }\end{array}$ & $\begin{array}{l}\text { Difficult to } \\
\text { perform }\end{array}$ & $\begin{array}{c}\text { Somewhat easy } \\
\text { to perform }\end{array}$ & $\begin{array}{l}\text { Very easy } \\
\text { to perform }\end{array}$ \\
\hline \multicolumn{6}{|c|}{ Please rate your ability to perform the below tasks on this simulator } \\
\hline Initial resection & $20 \%$ & - & - & $60 \%$ & $20 \%$ \\
\hline Subsequent resection & - & - & $60 \%$ & $20 \%$ & $20 \%$ \\
\hline Palpation of septal thickness & - & - & - & $60 \%$ & $40 \%$ \\
\hline
\end{tabular}

TABLE E2. Survey results for readiness for educational purpose

\begin{tabular}{lcccc}
\hline & $\begin{array}{c}\text { Requires complete } \\
\text { redesign }\end{array}$ & $\begin{array}{c}\text { Requires major } \\
\text { changes before use }\end{array}$ & $\begin{array}{c}\text { Requires small } \\
\text { changes before use }\end{array}$ & Can be used as is \\
\hline Readiness assessment for educational purpose & - & - & $80 \%$ & $20 \%$ \\
\hline
\end{tabular}

TABLE E3. Survey results for value of simulator as a teaching tool and relevance to practice

\begin{tabular}{|c|c|c|c|c|c|}
\hline & Don't know & No value & $\begin{array}{l}\text { Little } \\
\text { value }\end{array}$ & $\begin{array}{c}\text { Moderate } \\
\text { value }\end{array}$ & $\begin{array}{c}\text { Great deal } \\
\text { of value }\end{array}$ \\
\hline Please rate the value of the simulator as a teaching tool & - & - & - & $60 \%$ & $40 \%$ \\
\hline Relevance to practice, assuming employed as adult cardiac surgeon & $20 \%$ & - & - & $60 \%$ & $20 \%$ \\
\hline
\end{tabular}

TABLE E4. Survey results for value added

\begin{tabular}{|c|c|c|c|c|c|}
\hline & $\begin{array}{c}\text { No } \\
\text { value }\end{array}$ & $\begin{array}{l}\text { Little value, } \\
\text { not worth } \\
\text { the effort }\end{array}$ & $\begin{array}{l}\text { Modest value, } \\
\text { worth the effort }\end{array}$ & $\begin{array}{l}\text { High value, worth } \\
\text { the effort; would } \\
\text { perform myectomy } \\
\text { with senior partner }\end{array}$ & $\begin{array}{l}\text { High value, worth the } \\
\text { effort; would perform } \\
\text { myectomy independently }\end{array}$ \\
\hline \multicolumn{6}{|l|}{ Value added } \\
\hline $\begin{array}{l}\text { How would you rate this } \\
\text { experience with regard to } \\
\text { your comfort in } \\
\text { performing myectomy in } \\
\text { the future }\end{array}$ & - & - & - & $100 \%$ & - \\
\hline
\end{tabular}

